\title{
Manifestações inconscientes na relação líder-liderado: contribuições da teoria psicanalítica aos estudos organizacionais
}

Christiane Kleinübing Godol

UNIVERSIDADE do VALE do ITAJAí (UNIVALI), BIGUAÇU- SC, BRASIL

Fabíola RadaÊ GeWehr Cargnin

UNIVERSIDADE DO VALE DO ITAJAÍ (UNIVALI), BIGUAÇU- SC, BRASIL

ANTônIo GIOVANNI FIgLIUOLO UChôA

UNIVERSIDADE DO VALE DO ITAJAí (UNIVALI), BIGUAÇU- SC, BRASIL

\begin{abstract}
Resumo
Este estudo teve por objetivo compreender as manifestações inconscientes que transpassam a relação líder-liderado, nas organizações. Tais díades foram formadas por pares opositivos dependentes, quais sejam: transferência-contratransferência; projeção-introjeção; idealização-identificação - todos fenômenos construídos por Sigmund Freud como sendo da ordem do inconsciente. Na etapa teórica, partimos da historicidade da abordagem psicanalítica das organizações: a) a análise dos estudos psicanalíticos, desde o campo social ao campo organizacional (note-se que o próprio Freud diz ser o inconsciente também social); b) o centro da etapa teórica é constituído por uma leitura psicanalítica dos fenômenos da liderança; e c) a teorização sobre as três principais díades inconscientes que atuam na relação líder-liderado. Como método, utilizou-se a psicossociologia e a entrevista clínica de Lévy. A análise dos resultados inicialmente prevista nos objetivos precisou ser - por inúmeros motivos alterada durante a elaboração do artigo, uma vez que, na relação da díade transferência-contratransferência, encontra-se uma complexidade maior do que a esperada e que não poderia ser desperdiçada nas interpretações. Uma das relações mais evidenciadas nas conclusões foi visualizada e possibilita compreender melhor a maneira pela qual a identificação é engendrada a partir da relação dual entre a projeção e a introjeção.
\end{abstract}

Palavras-chave: Liderança. Psicanálise. Organizações.

\section{Unconscious manifestations in the leader-follower relationship: contributions of psychoanalytic theory to orga- nizational studies}

\begin{abstract}
This study aimed to understand the unconscious manifestations that transgress the leader-follower relationship in organizations. These dyads were formed by opposing dependent pairs, namely: transference-counter transference; projection-introjection; idealization-identification Freud's constructs and all of them unconscious phenomena. The theoretical framework presents the history of the psychoanalytic approach of organizations: a) the analysis of psychoanalytic studies, from the social field to the organizational field (considering that, according to Freud, the unconscious is social. In this section the reader will find a brief tour of the five so-called Sociological Studies of Freud); b) the core of the theoretical framework is already constituted by a psychoanalytic reading of the phenomena of leadership, and finally; c) the theory about the three main unconscious dyads that act in the leader-follower relationship. As a method, psycho-sociology and Lévy's clinical interview were used. The results allow psychoanalytic interpretations by identifying the presence of the dyads, in both leaders and followers discourse. The analysis of the results initially planned in the objectives of this study had to be - for many reasons - altered during the research. One of the reasons is that the relation transference-counter transference dyad found during the study was more complex than expected and that could not be ignored in the analysis. As one of the relations most evidenced, the analysis of the transference-counter transference dyad allows a better understanding of the way in which the identification is generated from the dual relationship between projection and introjection.
\end{abstract}

Keywords: Leadership. Psychoanalysis. Organizations.

\section{Manifestaciones inconscientes en la relación líder-liderado: contribuciones de la teoría psicoanalítica a los es- tudios organizacionales}

\section{Resumen}

Este estudio tuvo como objetivo comprender las manifestaciones inconscientes que tienen lugar en la relación líder-liderado en las organizaciones. Las díadas se formaron por pares de oposición dependientes, a saber: transferencia-contratransferencia; proyecciónintroyección; idealización-identificación, todos fenómenos construidos por Freud como pertenecientes al orden inconsciente. En la etapa teórica partimos de la historicidad del enfoque psicoanalítico de las organizaciones: a) el análisis de los estudios psicoanalíticos, del campo social al campo organizacional (nótese que el propio Freud dice que el inconsciente también es social. En este capítulo, el lector encontrará un breve recorrido por los cinco llamados Estudios Sociológicos de Freud); b) el centro de la etapa teórica se compone de una lectura psicoanalítica de los fenómenos de liderazgo; y c) la teorización sobre las tres principales díadas inconscientes que actúan en la relación líderliderado. Como método, se utilizó la psicosociología y la entrevista clínica de Lévy. Los resultados nos permiten armonizar interpretaciones psicoanalíticas identificando la presencia de las díadas tanto en los discursos de líderes como de liderados. El análisis de los resultados, previsto inicialmente en los objetivos, tuvo que ser alterado - por diversas razones - durante la elaboración del artículo, ya que en la relación de la díada transferencia-contratransferencia encontramos una complejidad mayor que la esperada y que no podría desaprovecharse en las interpretaciones. Se visualizó una de las relaciones más evidenciadas en las conclusiones, lo que posibilitó comprender mejor la manera como la identificación se engendra a partir de la relación dual entre la proyección y la introyección.

Palabras clave: Liderazgo. Psicoanálisis. Organizaciones. 


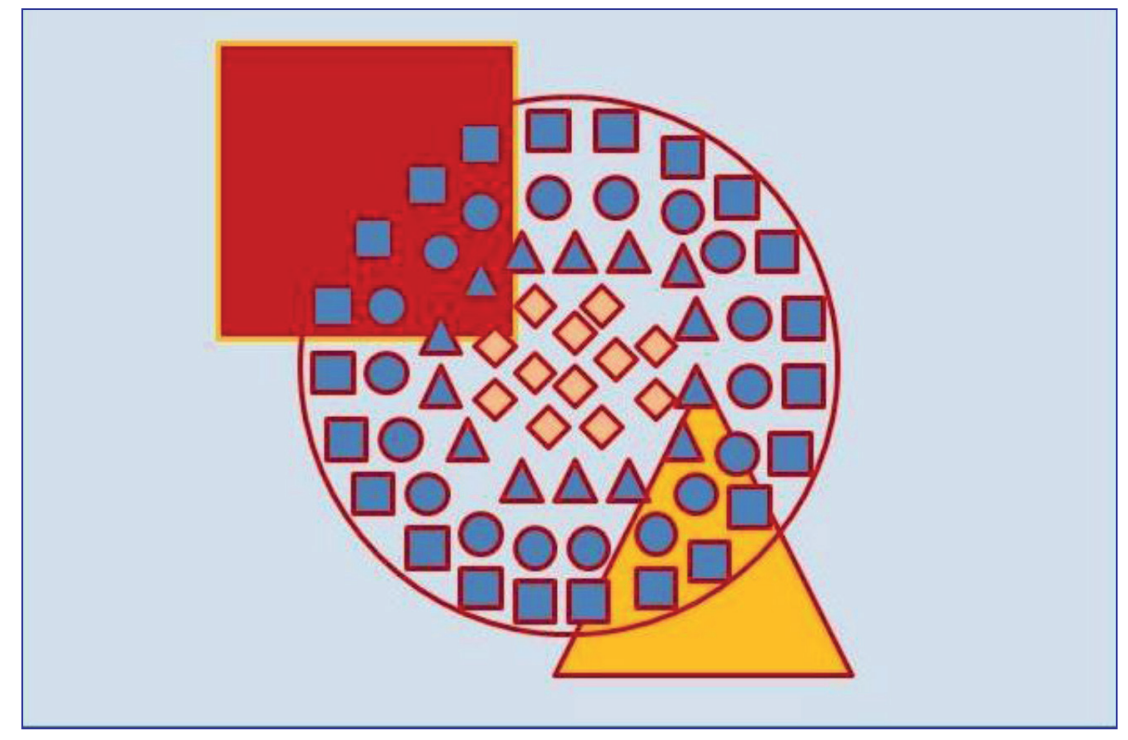

\section{INTRODUÇÃo}

A psicanálise constitui uma teoria sobre a psique humana individual, já que, de início, Sigmund Freud se preocupou com as enfermidades das histéricas e buscou um modo de oferecer-Ihes a cura. Entretanto, se ampliarmos seus ensaios teóricos, verificaremos que a psicanálise vai além dos domínios do indivíduo e, de acordo com Enriquez (1997), apresenta um arcabouço teórico que possibilita entender a relação indissociável entre o social e o individual. Dessa forma, ainda que psicanálise não tenha surgido para analisar o campo das organizações, os estudos sobre o inconsciente trouxeram uma nova possibilidade de ampliar o conhecimento sobre os fenômenos organizacionais, ao privilegiar os espaços da dimensão do discurso subjetivo, das fantasias e das emoções - na contramão dos pensamentos racionalistas e gerencialistas (GODOI, 2005; PAES e DELLAGNELO, 2015). Priorizar a racionalidade no campo das organizações implica renunciar a uma parte importante para a compreensão de qualquer tipo de relação humana, uma vez que o homem não é composto só de uma mente que funciona como um relógio, mas sim um sujeito com corpo e mente inseparáveis. Entendê-lo de forma fragmentada significa não entendê-lo em sua complexidade. As teorias gerencialistas que legitimam as atividades humanas em indicadores de desempenho, em competitividade organizacional e em performance, dificultam, no dizer de Gaulejac (2007), a conciliação entre as dimensões políticas, econômicas e sociais, fragmentando questões relativas ao bem-estar do homem.

É importante salientar que a teoria psicanalítica postulada por Freud leva em consideração uma lógica de um sujeito do inconsciente, que, por sua vez, é diferente daquele sujeito racional próprio da administração clássica. Este se refere àquele que não está limitado a suas faculdades mentais, pois é um sujeito que estabelece, além dos processos cognitivos, conexões não previstas, consigo e com os outros, baseadas em paixões. Para Enriquez (1997), tais paixões corresponderiam a fantasias inconscientes, imersas em desejos e ideias. Vale ressaltar que os estudos sobre fenômenos mais profundos das organizações que utilizam a psicanálise como orientação tomaram forma nos últimos 60 anos (ARNAUD, 2012), personificando-se na figura de Lapierre (1995), Gabriel (1995), Enriquez (1997), Maccoby (2004), Kaës (2011), Gabriel (2011), Arnaud (2012), Maltz (2012), Stein (2013), Driver (2013), Islam (2014), Stein e Allcorn (2014). Tais autores se dedicaram ao estudo da dinâmica das organizações e, por meio de seus insights sobre os aspectos irracionais, imaginários, emocionais e simbólicos, contribuíram com o avanço das discussões acerca dos fenômenos da liderança.

Esta pesquisa analisou as manifestações inconscientes na relação líder-liderado a partir da teoria psicanalítica. Além do arcabouço teórico adotado, o estudo foi pautado pelo método da psicologia e pela prática da entrevista clínicas - em setting organizacional -, e foram realizadas com 1 líder e 5 liderados, na tentativa de apresentar e discutir algumas manifestações

Fonte da imagem: Elaborado pelos autores. 
inconscientes que encobrem a liderança. Entretanto, como chegar ao conhecimento dessas manifestações inconscientes a partir de entrevistas clínicas, tendo um vista que se encontra em outro setting, que não o analítico? Além disso, como promover uma conversa que tem em si uma pergunta norteadora, embora ampla, que direcionou a conversa e não uma livre associação de ideias, técnica que Freud adotou? Para essas perguntas, recorreu-se à obra de Freud - que possibilitam pensar que o inconsciente não está nas profundezas da mente, mas sim, na superfície, por meio das formações inconscientes presentes nos discursos, acessível no consciente.

Compreender os elementos do universo inconsciente que encobrem a liderança, tendo em vista uma interlocução entre dois campos do saber - estudos organizacionais e psicanálise. Mais especificamente, tratou-se de compreender as manifestações dos inconscientes presentes na relação líder-liderado. Inicialmente foi proposto um breve histórico utilizando autores que se dedicam a pesquisas sobre emoções, subjetividade, liderança com base psicanalítica; logo, apresentamos de que sujeito do inconsciente o trabalho se ocupa, para apontar a ligação entre o inconsciente, a priori tão individual, e o social e, por fim, uma análise de alguns aspectos do inconsciente, para compreender a dinâmica do fenômeno da liderança.

O método subjetivo adotado neste estudo encontrou sua justificativa nas ideias de Lapierre (1995), por exemplo, autor que pressupõe que o conhecimento da liderança passa indubitavelmente pelo conhecimento da realidade interna do líder. Desse modo, a pesquisa em liderança se propôs a realizar uma escuta acerca das relações entre líder e liderados, buscando compreender as manifestações inconscientes ali presentes. As análises das entrevistas clínicas forneceram materiais significativos da história e da prática da liderança que foram, artesanalmente, sendo registradas com vistas a proporcionar ao leitor uma narrativa que o leve a compreender elementos que fazem parte da estrutura profunda da liderança, diferentes daquela difundida pelo olhar comportamental.

Para complementar, nas palavras de Freud (1982a), a resposta ao questionamento: de que forma podemos conhecer o inconsciente? Ele diz: "É claro que o conhecemos apenas enquanto consciente, depois que experimentou uma transposição ou tradução em algo consciente. Diariamente o trabalho psicanalítico nos traz a experiência de que é possível tal tradução".

Este estudo teve por objetivo compreender as manifestações inconscientes que transpassam a relação líder-liderado, nas organizações. Tais díades foram formadas por pares opositivos dependentes, quais sejam: transferência-contratransferência; projeção-introjeção; idealização-identificação - todos fenômenos construídos por Freud como sendo da ordem do inconsciente. $\mathrm{Na}$ etapa teórica partimos da historicidade da abordagem psicanalítica das organizações: a) a análise dos estudos psicanalíticos desde o social ao organizacional (note-se que o próprio Freud diz ser o inconsciente também social); b) o centro da etapa teórica é constituído já por uma leitura psicanalítica dos fenômenos da liderança; e c) a teorização sobre as três principais díades inconscientes que atuam na relação líder-liderado. Espera-se, por fim, contribuir com a elevação desse espaço crítico de traslado de conceitos originários de outra região de origem a outro campo do saber, com os devidos cuidados de não rompimento da estrutura epistêmica.

\section{PSICANÁLISE: DO CAMPO SOCIAL AO CAMPO DO ORGANIZACIONAL}

Para trabalharmos com o olhar da psicanálise sobre o fenômeno da liderança, mostra-se necessária uma breve passagem pela historicidade da psicanálise no contexto social, principalmente utilizando os escritos psicanalíticos de Freud. A proposição de um estudo psicanalítico associado ao campo social é enfatizada por Enriquez (1997), mostrando que não se trata de um uso inadequado da psicanálise, mas sim do fato de não ser possível pensar em uma psicanálise fora do plano social, uma vez que a constituição do sujeito se faz justamente pela entrada no social. Com isso, resta-nos pensar que a psicanálise autoriza a utilização de suas ideias para entender os fenômenos organizacionais.

Nas obras introdutórias de Freud (1982b), encontramos uma observação por ele difundida na primeira lição de psicanálise acerca de sua felicidade por encontrar na plateia de sua conferência uma maioria de ouvintes não médicos. Nota-se a partir disso que, desde o princípio, interessou para Freud que sua teoria não fosse privilégio da categoria médica, mas de pensadores de diversas áreas, inclusive as ciências sociais. Para Enriquez (1997), desde muito cedo, Freud mostrou interesse na discussão da relação entre psíquico e social. Em sua obra "O interesse científico da psicanálise", Freud (1982c) já alertava para a importância que os estudos da neurose e a nova concepção de sujeito do inconsciente poderiam proporcionar ao campo 
organizacional. Mais tarde, em "Totem e tabu", Freud (1982d) se empenhou em discutir as origens dos laços sociais e da própria civilização, trazendo contribuições com a antropologia ao dizer que o complexo de Édipo está na origem da civilização. O mito da horda primitiva e do pai totêmico seriam as bases para o nascimento das instituições sociais, da cultura, da família, da religião e da moralidade.

Em "Sobre o narcisismo", Freud (1982e) analisou a importância do Outro na constituição do Eu, da individualidade. Para o autor, a criança, ao nascer, é um ser indiferenciado do mundo e, à medida que encontra o desejo do outro, vai manifestando suas identificações, construindo seus ideais, suas defesas e seus alicerces. Entretanto, para que esse pequeno ser possa perceber-se como diferente da mãe, é preciso que ele mesmo reconheça que foi descolado dela, e isso só ocorre na medida em que esse Outro passa a existir internamente, ou seja, como referência, modelo subjetivo. Portanto, antes do Eu existe(m) o(s) Outro(s).

A partir das premissas psicanalíticas, evidenciou-se que havia algo além da consciência, trazendo à tona outro sentido às condutas humanas, de forma que as emoções e os comportamentos não ficaram somente à mercê da consciência, mas também de um lugar hipotético denominado inconsciente. Crer em uma condição inconsciente da mente, para Freud (1982b), é considerar que existe outro sujeito, desconhecido para nós, que produz sentido e ações, esquecimentos e sintomas, que são involuntários e escapam. É pela possibilidade da consciência não dar conta de perceber todos os atos, e por rechaçar esse material, que deciframos que há outro lugar responsável por isso e que sua inteligibilidade se dá por meio de outra sistemática.

Os atos conscientes do ser humano passam indubitavelmente pela via de um desejo. Freud formulou a ideia de determinismo psíquico para dizer que nada que realizamos ocorre por acaso, mas é fruto de um desejo inconsciente, de uma amarração psíquica em que operam o desejo proibido - id (isso) -, a lei/proibição - superego (supereu) - e a realidade - ego (eu). Ora, se o inconsciente tem por princípio a satisfação de desejos e a sociedade propõe regras que condenam a satisfação de desejos, ele encontra a via do disfarce para se satisfazer. É nesse momento que o papel de diversos mecanismos psíquicos entra em cena, a fim de auxiliar na realização de desejos, mas também na manutenção da civilização.

Se, em "Totem e tabu", Freud (1982d) descreve a gênese, o advento do social, em "Psicologia das massas e análise do eu", Freud (1982f) apresenta os mecanismos de funcionamento do social, concluindo que a psicologia individual também é, ao mesmo tempo, psicologia social. E, ainda, que todas as relações que até o presente constituíram o principal tema da pesquisa psicanalítica podem ser consideradas fenômenos sociais. Freud torna simplória a pretensão de um estudo das organizações e instituições que ignore o psiquismo individual e coletivo na explicação dos fenômenos sociais. Freud (1982f) apresenta, logo no início de seus escritos, que a psicologia que olha para o indivíduo em sua particularidade almeja compreender os modos pelos quais o sujeito busca a satisfação de suas pulsões, ou seja, que caminho percorre para se satisfazer. Entretanto, analisar tal individualidade se restringe a poucas situações. Já quando se leva em conta que esse sujeito pertence a uma massa e sofre influências das íntimas pessoas de seu nicho, assim como de outros não tão representativos, percebe-se o quanto sua constituição psíquica depende do grupo.

Ávila (2009), utilizando estudos de Freud, discute esse Eu em sua representação de "escritos sociológicos" internos, em que o sujeito é uma unidade independente, autônoma, individual; porém, isso expressa singularmente, um conjunto, uma coletividade correspondente. Desse modo, propõe cinco afirmações: a) o indivíduo não existe; b) o Eu é feito de relações; c) o Eu é múltiplo; d) o Eu é Eu-Outro; e, e) o Eu é plural.

Dito isso, quais são os elos que unem um sujeito ao campo social? Se recorrermos a Enriquez (1997), acerca das obras sociológicas de Freud, verificaremos que é o inconsciente que está diante desta ponte, demarcando um terreno vasto e primordial para o entendimento das condutas humanas. Entre o sujeito e o campo social há um saber oculto que faz movimentar essa malha de relações, pois o sujeito é possuidor de pulsões a ser saciadas e a sociedade, para existir, precisa impedir que tais desejos sejam postos à prova. Na medida em que o homem se afasta de suas programações mais instintivas, inerentes à raça, mais se ascende a uma parte mais humana. É esse o conceito retratado em “O mal-estar na civilização" (FREUD, 1982g). Para ele, há dois princípios fundamentais agindo sobre o indivíduo: o princípio do prazer e o princípio da realidade. Ambos os princípios regem o funcionamento psíquico e têm por missão moldar os caminhos da satisfação, de forma que seja possível atender às condições impostas pela ordem social. 
Godoi (2005) vem anunciar a importância da psicanálise como uma forma de pensar o sujeito, que é um ser complexo, dotado de dimensões racionais e irracionais. A psicanálise, tal como Godoi (2005) indica, coloca em evidência outro sentido para a vida organizacional, ou seja, como espaços em que se atravessam pulsões, angústias, ideais, diferentes identidades e desejos e, acima de tudo, reconhece as estranhezas e suas impossibilidades, conferindo à organização o sentido de organismo vivo. Mais recentemente, Lopes (2008) contribui com o cenário da psicanálise nos estudos organizacionais, no sentido de analisar os vínculos estabelecidos entre indivíduo e organização que caracterizam a permanência ou o expurgo da empresa familiar, a partir da abordagem psicanalítica e das teorias sobre o vínculo social. Um dos resultados encontrados e que autoriza a psicanálise como lente é o fato de que a permanência ou o expurgo não estão relacionados somente as questões organizacionais, mas também aquelas que provêm do contexto familiar. A contribuição de Guimarães (2014) consistiu no fato da autora propor uma metodologia de cunho psicanalítico para compreender como as vivências e as construções subjetivas de executivos influenciavam as escolhas em sua trajetória profissional.

A psicanálise, por sua vez, apresenta um modo de compreensão sobre a questão da vida que muitos podem contestar - ou propor outras orientações. Contudo, uma coisa é inegável: que a ponte que estabelece com o campo social permite-nos continuar dizendo que não é uma ciência do indivíduo, pois seu próprio sujeito se funde com o social, permitindo a existência dele. Por fim, Gaulejac (2007) salienta que as organizações precisam ir além de uma psicologia comportamental e introduzir a psicologia crítica e a psicanálise como formas de compreender a essência da organização, pois essas abordagens apresentam ideias que possibilitam uma compreensão mais profunda do mundo em que vivemos.

\section{UMA LEITURA PSICANALÍTICA DO FENÔMENO DA LIDERANÇA}

Ao aproximar dois campos de conhecimento - psicanálise e organizações -, é fundamental apresentar a noção do sujeito do inconsciente com a qual este estudo se ocupou. Isso se mostra necessário porque o pensamento, que tende à racionalidade, e o conceito de controle, como analisa Gabriel (1995), por muito tempo, estiveram presentes no discurso sobre o que era uma organização e o que dela precisava ser analisado.

Para analisar os fenômenos da liderança sob a ótica da psicanálise, é importante ter em mente que o inconsciente não está nas profundezas da mente, mas disponível no consciente, para que o analista, conhecedor da psicanálise, o interprete. Para compreender melhor essa consideração, vale recorrer a uma passagem de "O inconsciente", onde Freud (1982a) apresenta um questionamento: de que forma podemos chegar ao conhecimento do inconsciente? É claro que o conhecemos apenas como consciente, depois que experimentou uma transposição ou tradução em algo consciente. Diariamente, o trabalho psicanalítico nos traz a experiência de que é possível tal tradução (FREUD, 1982a). Dito de outra forma, as condensações, os deslocamentos e as associações e, de outro modo, os chistes, os atos falhos, as ideias e as metáforas também são vistos pela psicanálise como materiais inconscientes, mas que aparecem sob a expressão consciente. Sobre essas manifestações Freud (1982a) relata que tanto em pessoas sadias como em doentes verificam-se com frequência atos psíquicos que pressupõem, para sua explicação, outros atos de que a consciência não dá testemunho. Esses atos não são apenas as ações falhas e os sonhos dos indivíduos sadios e tudo que é chamado de sintomas e fenômenos obsessivos na psique dos doentes - nossa experiência cotidiana mais pessoal nos familiariza com pensamentos espontâneos, cuja origem não conhecemos, e com resultados espontâneos cuja elaboração permanece oculta pra nós. Todos esses atos conscientes permanecem desconexos e incompreensíveis se insistimos na pretensão de que por meio da consciência experimentamos tudo o que nos sucede em matéria de atos psíquicos, mas se inscreve em uma coerência demonstrável se nesse material interpolamos os atos inconscientes inferidos (FREUD, 1982a).

Analisar as obras sociológicas de Freud, tendo em vista o conhecimento exposto, parece-nos mais fácil se constatamos que as manifestações inconscientes são importantes para compreender um cenário mais profundo em torno do fenômeno da liderança. Em "Psicologia das massas e análise do eu", Freud (1982f) analisou de que forma o eu se constitui a partir de sua relação com a massa social, ou seja, acreditava que o "Eu" e a "massa" eram partes constitutivas de um mesmo engodo. Com isso, trouxe uma extensa discussão sobre questões que se referem à dinâmica psíquica, assim como à psicologia das massas. Para ele, havia algo que unia os componentes de um grupo, formando uma massa, em uma só unidade, e isso só poderia estar ligado ao que era comum a todos os envolvidos, ou seja, ao fenômeno da liderança. 
O grupo tem o desejo de organizar-se diante de um líder; mas, para que isso ocorra, o líder precisa acreditar fielmente em suas próprias ideias para corresponder e influenciar o grupo. Esse conjunto de desejos e necessidades coloca a liderança como um emaranhado, que forma uma "massa psicológica" constituindo uma cola imaginária entre os sujeitos da tribo. Para Freud, o efeito dessa massa é capaz de produzir criações extraordinárias, pois há uma contemplação entre subjetividades que enriquece o processo da imaginação, efeito que o indivíduo diante da solidão jamais poderia produzir. Ao estudar a liderança nas organizações, autores como Lapierre (1995), Maccoby (2004), Gabriel (2011), Driver (2013), Krohn (2012), Lichtman (2012), Humphreys, Zhao, Ingram et al. (2010), Vince e Mazen (2014) propuseram ideias que convergem com esse pensamento que Freud apresentou. Para eles, a liderança é constituída por um universo fantasmático que vai além das formalidades políticas do cargo e do discurso de uma relação imaginária estabelecida entre líder e liderado.

O que vai definir o fenômeno liderança, sob o olhar de Lapierre (1995), é a vida psíquica do líder, ou seja, as emoções que externaliza, a forma como percebe o mundo e como age com os outros e se comporta. Isso implica dizer que há uma dimensão inconsciente que emerge nas relações humanas, um mundo fantasmático que vai além das características e das habilidades pessoais e que se conecta com o mundo exterior por meio de um jeito de ser, um modo de pensar, um modo de fazer. Discurso de liderança, portanto, é considerar essa dimensão. Se a vida interior do líder é tão importante para a compreensão da liderança e tão decisiva quanto o direcionamento diante de sua equipe, é fundamental que ele mesmo tome consciência de seus fantasmas, de seus medos, de suas reações, pois ou será vítima desses anseios inconscientes ou tornará sua equipe vítima deles.

Kets de Vries (2003) apresenta sua visão do lado negro da liderança. Para ele, a maior doença dos líderes, especialmente do chief executive officer (CEO), é o narcisismo, porém, acredita que uma dose de narcisismo é importante nesse cargo, propondo uma distinção entre o narcisismo reativo e outro que é construtivo. Os narcisistas construtivos seriam aqueles que têm uma boa base familiar, com estrutura de segurança que dá suporte para saber o que se quer, e também para que as decisões se tornem mais assertivas, porém, não são tão envolvidos com os outros, apesar de garantirem uma boa convivência. Já os reativos são os patológicos egoístas com os outros e que não valorizam o fator humano. Conforme suas análises, muitas são as variações de narcisistas reativos.

Já Kaës (2011) apresenta o conceito de intersubjetividade, que é uma perspectiva interacional que vai muito além de uma simples interação subjetiva ou comportamental entre as pessoas do grupo. A intersubjetividade é o compartilhamento ou a interlocução dos sujeitos e de suas formações do inconsciente - fantasias, recalques, desejos, proibições essenciais. Para compreendê-la, portanto, é preciso recorrer à lógica dos processos psíquicos, de formação interna e das correlações entre as subjetividades em jogo. Nessa lógica, uma não existe sem a outra e sem seu conjunto formador; ou seja, em um grupo, o sujeito é parte constituída e constitutiva.

Alguns líderes são capazes de despertar, em seu grupo, sentimentos construtivos, de força, de comprometimento; enquanto outros podem fazer enaltecer os mais agressivos gestos de terror e destruição. Entretanto, para ser líder, embora seja necessária uma flexibilização diante das diferentes situações e pessoas com as quais vai se relacionar, só exercerá liderança se seus seguidores estiverem em consonância. Tal consonância, para Maccoby (2004), está relacionada a uma cola emocional estabelecida entre líder e liderado, pela qual sentimentos bons ou ruins são transferidos de uns para os outros, dependendo do mundo interno de cada um. Deste modo, o poder do seguidor que transfere é tão importante quanto o poder do próprio líder que contratransfere. Tomando este termo emprestado da psicanálise, Maccoby (2004) contribui com o estudo da liderança ao apresentar a ideia que entre líder e liderado há uma relação transferencial significativa e que estaria no cerne da própria liderança. Para o autor, os seguidores projetam seus sentimentos e experiências infantis para o líder e o líder responde a elas, a partir de seus fantasmas infantis. Desse modo se dá a transferência e a contratransferência entre eles. Entretanto, nem sempre essa via de mão dupla ocorre de forma positiva e o perigo está no momento em que o líder não sabe trabalhar com tal dinâmica e age de modo a incentivar sentimentos irreais em torno de sua liderança. Essa observação contribui para que se possa perceber que não estamos atribuindo conceitos psicanalíticos à organização, mas trazendo suas contribuições com a análise dos fenômenos que lá são estabelecidos.

Para complementar, recorremos às ideias de Kets de Vries (2003), ao assinalar que a posição que um líder exerce favorece projeções das fantasias dos liderados sobre as expectativas em torno da liderança. Tidos como heróis, poderosos e salvadores, retroalimentam um sentimento de onipotência próprio do desejo do homem. Entretanto, toda essa idealização está 
condenada ao fracasso, à decepção dos liderados, quando os líderes não conseguem satisfazer todas as fantasias dirigidas a ele e passam de heróis a vilões.

A liderança, portanto, é construída imaginariamente e, invariavelmente, está sujeita a falhas, reafirmando que o ser é falta, ou seja, incompleto. Driver (2013), em sua pesquisa, para a qual foram entrevistados 15 líderes, procurou investigar qual é o sentido dessas faltas e chegou à conclusão de que a identidade dos líderes é submetida por desejos inconscientes e, portanto, menos poderosa do que podemos pensar no que diz respeito à imposição de uma estrutura sobre os liderados, mas muito mais poderosa do que imaginamos em função dos seres imaginários que possuem em sua vida interior.

\section{SOBRE AS DÍADES DAS FORMAÇÕES DO INCONSCIENTE NA RELAÇÃO LÍDER-LIDERADO}

Na teorização a seguir, o leitor encontrará definição e discussão, principalmente centradas em Freud e Laplanche e Pontalis (2001) das três díades - manifestações do inconsciente - que compõem objetos de análise deste estudo. A partir das obras sequenciais de Freud, procuramos, sem nos prolongar, o significado central de cada conceito que, por sua vez, encontra em Laplanche e Pontalis (2001) uma noção bem mais elaborada pelo fato de que os autores do Vocabulário da psicanálise construíram as definições a partir do estudo de sua transmutação em toda a obra de Freud. Sempre iniciamos a compreensão do par opositivo dependente - díade - pelo primeiro conceito, tal como é conhecido, e assim foi historicizado por Freud, procurando, quando possível, integrar a teorização da díade ao final.

\section{Primeira díade: transferência-contratransferência na relação líder-liderado}

O par opositivo dependente transferência e contratransferência emergiu na obra de Freud em diferentes épocas. No que tange à noção de transferência, Freud (1982h) a definiu como processo pelo qual os desejos inconscientes se atualizam sobre determinados objetos, em um tipo de setting da relação psicanalítica, estabelecida entre o analisado e o analista. A transferência indicam Laplanche e Pontalis (2001) - é classicamente reconhecida como o terreno em que se joga a problemática de um tratamento psicanalítico, pois constitui a instalação, as modalidades, a interpretação e a resolução que caracterizam tal tratamento.

A contratransferência - o lado opositor dessa díade - foi construída somente 25 anos depois, em Cinco lições de psicanálise (FREUD, 1982b). Laplanche e Pontalis (2001) indicam que Freud conceituou o fenômeno contratransferencial como sendo resultado da influência do paciente sobre seus sentimentos inconscientes do médico. Baseado nessa relação, o analista produz ou deveria produzir, em sua complexidade, resistências internas, em uma constante autoanálise no contato com seus pacientes. Caso contrário, a falha em produzir essa autoanálise e o processo de resistência ao analista leva ao impedimento de tratar pacientes pela análise. Em comum com o significado, a contratransferência é definida por Laplanche e Pontalis (2001) ao relatar a relação entre analista e paciente sob o ponto de vista do analista e suas reações inconscientes à pessoa em análise e, sublinham os autores, as reações à própria transferência. Trata-se, portanto, do conjunto das reações inconscientes do analista ao sujeito analisado e, mais particularmente, à transferência deste (LAPLANCHE e PONTALIS, 2001; FREUD, 1982b). Sob o ponto de vista da delimitação do conceito, trasladado para a relação líder-liderado, podemos inferir que a personalidade do líder pode intervir na relação ou que a personalidade deste limita a relação, impede o fenômeno contratransferencial.

\section{Segunda díade: projeção-introjeção}

O termo projeção é utilizado, segundo Laplanche e Pontalis (2001), como a operação pela qual o indivíduo expulsa de si e localiza em outras pessoas ou coisas, qualidades, sentimentos, desejos e até "objetos" - de que ele desdenha ou recusa em si.

Introjeção, ao revés, consiste no processo evidenciado pela investigação analítica: o indivíduo. A introjeção aproxima-se da incorporação, que constitui seu protótipo corporal, mas não implica necessariamente uma referência ao limite corporal (introjeção Eu, no ideal do Eu).

A projeção e a introjeção, como processos, estão relacionadas intimamente à identificação, uma vez que na introjeção o sujeito incorpora algo do outro que lhe causa prazer, enquanto que na projeção ele expulsa algo que é seu, põe para fora, pois Ihe causa desprazer (FREUD, 1982i). 


\section{Terceira díade: idealização-identificação}

Idealização é entendida historicamente (FREUD, 1982e; 1982j) como um processo psíquico pelo qual as qualidades e o valor do objeto são levados à perfeição. Laplanche e Pontalis (2001) ajudam a entender a diferenciação interna do conceito de idealização em outros dois fenômenos. A identificação com o objeto idealizado contribui com a formação e o enriquecimento das chamadas instâncias ideais da pessoa (Eu ideal, ideal do Eu). O Eu ideal consiste na formação intrapsíquica e é definido como um ideal narcísico de onipotência forjado a partir do modelo do narcisismo infantil. Por outro lado, a expressão ideal do Eu utilizada por Freud em sua segunda tópica do aparelho psíquico, como instância da personalidade resultante da convergência do narcisismo (Eu ideal) e das identificações com os pais, com seus substitutos e com os ideais coletivos. Enquanto instância diferenciada, o ideal do Eu constitui um modelo ao qual o indivíduo procura conformar-se. O primeiro passo para que possamos compreender o processo de idealização é termos em vista que projetamos sempre alguma coisa de nós mesmos que nos faz ver essas realidades parcialmente segundo nossos desejos. É sempre sua própria visão que se aprecia (ou que se rejeita) quando se está fascinado ou perturbado pela visão de um líder (LAPIERRE, 1995).

O par opositivo dependente da idealização, ou seja, a identificação - processo psicológico pelo qual um indivíduo assimila um aspecto, uma propriedade, um atributo do outro e transforma-se, total ou parcialmente, segundo o modelo dessa pessoa. A personalidade constitui-se e diferencia-se por uma série de identificação (FREUD, 1982d; 1982k).

Por meio da identificação, o sujeito assimila um aspecto que é do outro e transforma-se de maneira total ou parcial, segundo esse modelo, transformando seus ideais. Esses aspectos são caracterizados por um valor, um atributo, algo do outro que, de alguma forma, é significativo para ele. A identificação abrange outros conceitos psicológicos como a imitação, a empatia, a simpatia, o contágio mental, a projeção, a introjeção - e é o modo como o sujeito se constitui como ser humano (LAPLANCHE e PONTALIS, 2001).

Por fim, tal como verificaremos nas análises dos resultados, as três díades inconscientes que compõem a relação líder-liderados, nem sempre se manifestam de forma linear ou como par opositivo dependente, podendo ocorrer cruzamentos previstos na trama da historicidade dos conceitos freudianos.

\section{METODOLOGIA}

Esta seção apresenta o método principal utilizado na pesquisa de campo-psicossociologia (LÉVY, 2001; LÉVY, NICOLAï, ENRIQUEZ et al., 2001) -, bem como, a técnica - ou melhor, "prática" - de coleta de discursos, denominada entrevista clínica (LÉVY, 2001; LÉVY, NICOLAÏ, ENRIQUEZ et al., 2001) e, por fim, dois eixos centrais - condensação e deslocamento -, também originários de Freud, acerca dos quais, por vezes, amparamo-nos como auxiliares originários da teoria psicanalítica, para interpretações dos opositivos dependentes.

\section{Delineamento do estudo e práticas de coleta e análise de dados}

A pesquisa foi realizada em uma universidade na Região Sul do Brasil e contou com a participação de 1 coordenador de curso de pós-graduação stricto sensu, bem como de 5 professores que atuam nesse programa. Foram 1 mulher e 4 homens, com formação, tempo no programa e faixa diferentes. Os critérios de escolha dessa organização e dos participantes da pesquisa (líder e liderados) foram consecutivamente por acessibilidade e possibilidade de abertura de entrada no campo, bem como daqueles que estavam pré-dispostos ao discurso. A cena analítica, nesse caso a intervenção psicossociológica é uma situação "artificial", "de laboratório", pois sempre rompe com o cotidiano.

Ao trabalhar com sujeitos concretos, vivos, exprimindo-se livremente, a intervenção psicossociológica cria fatos inteligíveis, "purificados". Permite a emergência de sentidos não preestabelecidos, mas construídos na situação de interação (e interlocução). Apoia-se em significações que os próprios atores descobrem, elaboram, colocam em discurso e que podem ser captadas por meio de análise. As mudanças de sentido ao longo do processo, e que o legitimam, fazem do discurso a verdade da intervenção e a verdade do fato psicossocial (MACHADO, 2010). 
Como prática de coleta de dados foram utilizadas as entrevistas clínicas (LÉVY, 2001; LÉVY, NICOLAï, ENRIQUEZ et al., 2001), com o intuito de analisar narrativas que pudessem apresentar manifestações inconscientes para um estudo mais aprofundado sobre a liderança. Para Lévy (2001), esse tipo de entrevista é uma forma de interrogatório que busca, por meio da reciprocidade entre entrevistado e entrevistador, compreender os saberes que os membros de um grupo têm a respeito de seu próprio grupo. A entrevista clínica é, ainda, um dispositivo que leva as pessoas que participaram da pesquisa a rememorar suas experiências de vida, suas lembranças, suas percepções e os acontecimentos. Ainda que com mais coincidências do que divergências, a entrevista clínica apresenta uma abordagem diferenciada da conhecida em pesquisa qualitativa, "entrevista em profundidade" (GODOI e MATTOS, 2010), que pretende apenas - sendo aberta ou com roteiros semiestruturados - compreender a forma como o sujeito constrói os significados dos conceitos por nós estudados. Dessa forma, a entrevista clínica se aproxima mais da noção inerente às práticas da entrevista oral de vida, que (re)constrói os significados da experiência vivida pelos sujeitos.

\section{ANÁLISE DA RELAÇÃO LÍDER-LIDERADOS A PARTIR DOS CONCEITOS PSICANALÍTICOS}

Da mesma forma que na teorização acerca das díades que se manifestam na relação inconsciente líder-liderado, o leitor encontrará aqui as análises - na mesma sequência - tecidas de forma psicanalítica, contendo representações gráficas (topográficas) capazes de sintetizar, em um primeiro momento, o discurso contratransferencial do líder em relação aos cinco demais liderados. A seguir, os eixos são configurados - não importando priorização de sujeito -, mas sim a sequência das díades manifestas na relação líder-liderado, tal como teorizadas na última seção.

\section{ANÁLISE DAS MANIFESTAÇÕES DAS DÍADES INCONSCIENTES NOS DISCURSOS DOS ENTREVISTADOS}

\section{Contratransferência da liderança estudada: analisando coerências e atravessamentos entre as próprias díades}

Acerca da contratransferência, trata-se de um tema complexo, inesgotável e que atua em grande parte fora do setting analítico, proclama Freud (1982h) - e foi exatamente o que se observou em todo o discurso do líder, que demonstrava alegria e entusiasmo ao narrar e referir-se ao seu grupo. Desse modo, o discurso sobre o tema liderança foi algo que mobilizou a história de vida do líder e, perceptivelmente, trouxe-Ihe lembranças, memórias que o fizeram entrar na cena da entrevista clínica justamente devido à temática que circunstanciava o próprio tema investigado.

Na maior parte dos discursos, o líder, evidentemente - por estar respondendo a um aluno de outro programa stricto sensu - refere-se à coletividade, ao seu programa como um todo - fato este que poderia ser interpretado como "discurso institucional" - em seu sentido pejorativo -, o que não ocorreu em nenhum momento, mas sim o que transpassa a maioria de seu discurso é que ele separa vida pessoal e vida no trabalho, não se referindo a um dos entrevistados em específico, tal como evidenciado nos trechos abaixo:

Acreditar que a vida seja mais importante do que as obrigações formais, trabalho, escrever papers, avaliar tese e coisas do gênero. Isso é importante, mas viver é mais importante ainda. Então, a gente tem que saber que a nossa trajetória no planeta é finita e a gente precisa curtir a vida. Então, trabalhar não necessariamente precisa ser uma coisa pesada, chata, desagradável. (Discurso do líder)

Que sejam pessoas bem resolvidas, de bem com a vida, que o trabalho seja algo que as pessoas sintam prazer. E que o trabalho não pode estar dissociado da experiência de vida de cada um. Pelo menos é a leitura que eu faço em relação ao processo de gestão, ir para o trabalho com alguma dose, eu diria, 
de satisfação. Que não haja essa relação de opressão no ambiente de trabalho, clima de tensão. Eu tento passar isso, que as pessoas, de um modo geral, priorizem a informalidade. (Discurso do líder)

[...] tem que ter bom humor... brinco e quando percebo alguma [coisa] engraçada entre os professores, eu comento: "Ah, vocês não sabem da última do fulano de tal!" Aí, todo mundo cai na gargalhada. (Discurso do Líder)

Então, eu acho assim, isso é uma brincadeira, mas ou ele é um cara altruísta, que colhe o que planta, ou ele é um habilíssimo egoísta, no cumprimento de suas metas, que entendeu que o altruísmo é o seu melhor modo operante. Eu acredito na primeira opção no caso do Líder. (Professor 4)

Da análise, das intepretações articuladas dos discursos do líder, emergem algumas perspectivas: a) preocupação do líder com a coletividade equilibrada entre as diversas esferas da vida dos liderado - "eu tento passar isso", transmitindo o que foi observado na quase totalidade dos discursos dos demais professores - altruísta como que deseja que o grupo introjete seus valores, seu estilo e, consequentemente, suas metas; b) estilo narrativo irônico e sarcástico, a fim de manter um bom ambiente; c) entretanto, observe-se no discurso do Professor 4 a duplicidade da real intenção inconsciente dessas preocupações do líder, na medida em que esse professor chega a duvidar de ser o líder um "altruísta brincalhão" ou um "egoísta habilidoso"; d) note-se, ainda, que na fala introdutória do Professor 4 transparece o elemento irônico e "sarcástico" bastante fluente nos trechos narcisistas de autodefinição do líder, porém, também "contraironizando" o ambiente.

Muito fácil, portanto, seria pinçar trechos e todas as demais díades narradas pelos entrevistados - e assim realmente o são como genericamente transferência, formando um par perfeito e harmônico com o discurso do líder, no que tange ao ambiente de trabalho.

A partir da análise contratransferencial dos discursos do líder como um todo, começou-se a perceber que se havia instaurado e fixado no programa uma "cultura da felicidade mútua" - inclusive bastante diferenciada da própria organização onde prevalece o recalcamento, a repressão e as demais formas de sofrimento no trabalho. $O$ argumento central quer dizer que a totalidade de todos os elogiosos e "bajulatórios" discursos referentes ao líder podem ter sido gerados em virtude dessa cultura. Portanto, passou-se a "duvidar" da obviedade da autenticidade dos discursos, podendo estes estar refletindo - pelo menos em parte - o discurso institucional instaurado no programa como dispositivo automático gerador de identificação inconsciente entre os liderados. Tais motivos, aqui, para modificação parcial das conjecturas iniciais devem-se em virtude de: a) pequeno tamanho da amostra; b) a entrevistadora pertencer a outro programa da instituição e já ter mantido um relacionamento prévio com o líder, como seu antigo professor; c) simploriedade da transferência quando interpretada fora do setting analítico; d) noção da barreira produzida pelo discurso institucional, principalmente considerando que as entrevistas foram realizadas dentro do ambiente de trabalho. Conclui-se, até o momento, que o extremo carisma do líder pode ter sido capaz de gerar no grupo uma espécie de êxtase e perda da identidade na veneração ao líder. Por esse motivo, passamos a partir de agora a analisar as manifestações inconscientes atuantes na relação líder-liderado de forma isolada, agrupando-as e ilustrando-as sempre que possível. 
Figura 1

\section{Díade da idealização}

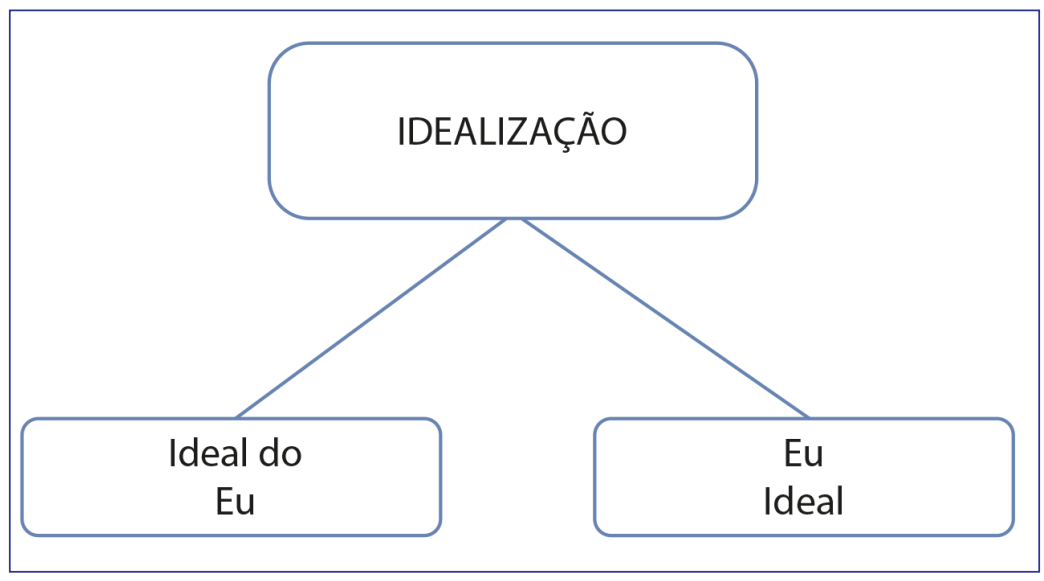

Fonte: Elaborada pelos autores.

\section{Idealização: ideal do Eu}

Ainda que tenhamos iniciado com a interpretação da contratransferência, prioritariamente cabe narrar, desde logo, um interessante atravessamento emergido de imediato no discursivo entre díades emitidas de forma inconsciente, na maior parte dos trechos do líder, que venha talvez por desmistificar uma relação aparentemente óbvia a ser aqui observada pelo leitor de existência de uma relação unânime de idolatria e veneração ao líder, em caso de uma leitura desavisada. Atravessamento tal entre díades previsto por Freud (1982j). Prosseguindo, nesse caso, supõe-se que somente uma parte daquilo que foi vivido desde a infância como modelo "está à disposição da personalidade consciente, enquanto que as outras pulsões foram detidas e podem não estar disponíveis à consciência". Probabilisticamente, podemos interpretar que essa outra parte, não acessível à consciência, sobre seu modelo de liderança poderá ser analisada a partir do que os liderados relatam sobre o líder ou também por meio do que escapou como manifestação inconsciente durante o discurso. Neste último caso, notou-se que o escape se deu, principalmente, em forma de chiste em que o líder, a partir de risos e da leveza das colocações, tentou apresentar uma esfera central da díade contratransferencial a qual passamos a analisar agora. Durante toda a entrevista, aparece no discurso do líder a alusão à palavra "brincar", referindo-se a seu modelo de liderança. Em grande parte dos trechos, comenta:

[...] porque a gente brinca muito [...] e quando percebo alguma coisa engraçada entre o que os professores mencionaram, eu comento: "Ah, vocês não sabem da última do fulano de tal! Aí, todo mundo cai na gargalhada". (Discurso do líder)

Essa referência pode estar associada, probabilisticamente, à forte instância narcisista freudiana, nesse caso relacionada à noção de um perfil de liderança engendrada desde as instâncias parentais denominadas - e teorizadas por Freud (1982h) - ideal do Eu. Note-se que se trata, aqui, de processos de identificação simbólica construídos, ao longo da vida, por algum traço diferenciado de uma imitação mimética e imaginária como em seu par opositivo dependente Eu ideal - que também compõe o conceito de idealização. Na Figura 1 se visualiza, inicialmente, a forma como a teoria psicanalítica percebe o vínculo entre o fenômeno da idealização por parte dos liderados com o líder.

Líder é um cara que sabe filosofar, mas sabe fazer. Essa é outra coisa que queria imitar também, só que eu venho do lado de lá, eu venho do lado do fazer, então, no meu caso digamos, eu tenho que aprender a pensar melhor, assim eu me imponho nesse desafio. (Professor 5) 


\section{Idealização: Eu ideal}

Os cinco conceitos centrais deste estudo vinculam-se diretamente à noção de contratransferência. Seguiremos, portanto, a ordem prevista por nós anteriormente. Portanto, a próxima noção a ser descrita é o par da idealização já bastante comentado como ideal do Eu. Falta-nos, agora, abordar o Eu ideal.

Passamos agora, em complemento ao conceito de idealização e de suas duas noções internalizadas na Figura 1, a adentrar o discurso dos liderados acerca de todos os demais conceitos inerentes tanto à teoria freudiana quanto à nossa intencionalidade inicial de trabalhar de forma linear as díades, quais sejam, as manifestações do inconsciente que compunham, isto é, faziam parte da teoria dos pares opositivos dependentes presentes em nossos objetivos iniciais.

O ideal mesmo seria clonar ele e botar uns 12, 15 líderes, assim, pela universidade e olha, essa universidade ia ser, olha, posso fantasiar esse cenário aí? (Professor 4)

\section{Figura 2}

Relação projeção-introjeção e identificação

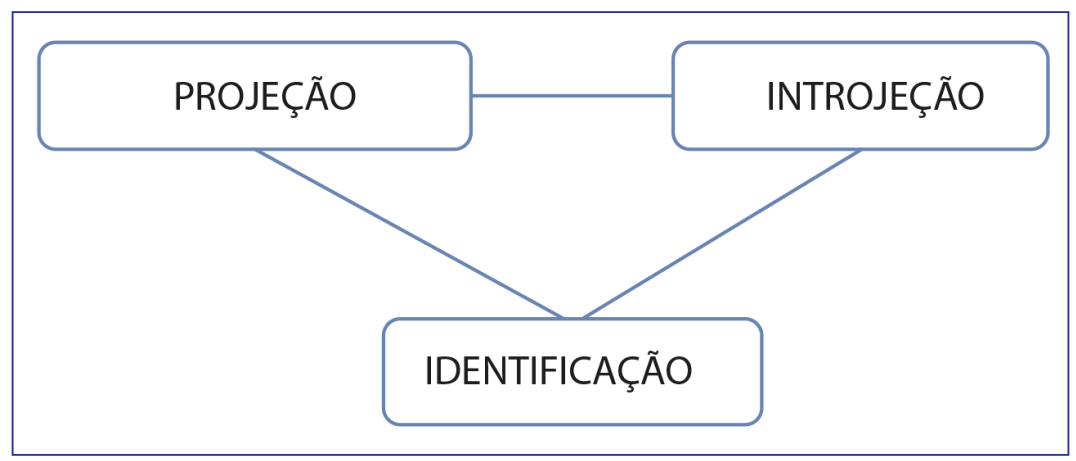

Fonte: Elaborada pelos autores.

\section{Projeção}

Ao cometer a clássica denegação freudiana (significa que o sistema inconsciente desconhece o "não" - logo se o sujeito "afirma e nega - sem ninguém tê-lo questionado, como no trecho abaixo; ou nega duas vezes, o inconsciente entende como "afirmação" - é provável que ele não goste tanto assim), o Professor 3 praticamente acaba por dizer que não gosta de seu lugar e do ambiente de convivência - projetando, assim, um objeto negativo seu para o exterior (Figura 2) - e afirmando seu oposto, que não se trata de um comprometimento afetivo, mas sim de um instrumento ligado à necessidade (instrumental, calculativo), cuja ordem não fica totalmente esclarecida, mas se evidencia em um "eu preciso" - ou seja, "alimentar" -, poderíamos nos interrogar entre a necessidade financeira ou do Eu.

Pra mim, assim, eu gosto de estar lá, se eu não gostasse, eu não estava lá, né, não é bem assim, eu preciso ou não preciso, que é para alimentar o Eu, alimentar o conhecimento, alimentar alguma coisa. (Professor 3)

\section{Introjeção}

Na concepção da historicidade freudiana, a partir conceito de projeção (incorporar "objetos bons") em junção com a o conceito de introjeção (o sujeito faz passar de forma imaginária qualidades inerentes a esses objetos), dando, por fim, origem ao processo de introjeção. A ideia de "clonar" o líder e espalhar vários deles pela Universidade mostra um desejo - contrário ao da projeção - de introjetar em si coisas que são apenas do líder e da sua concepção imaginária do líder. 
Este líder aqui, do nosso mestrado [...] é um grande líder. Eu usaria ele como referência de humanidade [...] ele é aquele que é reconhecido, acolhido, amado por aquilo que ele é como ser humano que conhece, tem conhecimento. (Professor 1 )

\section{Identificação}

Laplanche e Pontalis (2001) indicam que a identificação está profundamente relacionada à introjeção. Diferença fundamental reside no fato de que, enquanto a identificação é objetal - oposto da projeção -, a identificação é com as qualidades específicas desse objeto.

É um cara diferente, a universidade deveria tirar xerox dele, cola esse cara. Não adianta nem dizer, Castor, senta aqui do lado, olha e faz tudo igual, porque meu modelo mental não é o dele, meu jeito de fazer seria diferente do jeito de fazer dele, o ideal mesmo seria clonar ele. (Professor 4)

\section{CONSIDERAÇÕES FINAIS}

Não é possível pinçar, tomar emprestado momentaneamente uma partícula que surgiu originariamente da articulação com outros conceitos vinculados a determinado objeto, em um momento histórico preciso. O não domínio da amplitude do sistema que envolve o conceito original é o obstáculo responsável pelo atraso das intenções transdisciplinares e pelas frágeis formulações e práticas híbridas. Lançar mão de um conceito psicanalítico é arrastar junto a base epistemológica (a Weltanschauung, a noção de sujeito, as relações de objeto, a racionalidade e as implicações éticas) e a trama dos conceitos que formam o campo psicanalítico, onde um se remete multidirecionalmente ao outro, constituindo uma cadeia (GODOI, 2005).

A articulação com a psicanálise visa a permitir aos estudos organizacionais o defrontamento com as próprias faltas, com a impossibilidade de tudo tematizar a partir de si próprio, com a inexistência da reflexão total. Funcionando como o Outro, revelando o "outro cenário" do palco organizacional. A psicanálise possibilitaria às ciências que atuam nas organizações pensar melhor sobre si, destituindo-as do pedestal ilusório da completude.

O inconsciente - objeto da psicanálise - marca o grau de autonomia em relação à subjetivação - distanciando o sujeito das classificações estatísticas e massificadoras. O sujeito do inconsciente é o responsável pela pluriformidade incomensurável das singularidades organizacionais, para além das formalidades. O eu aparente, enquanto isso, é formado pelo jogo de deformações constitutivas e, simultaneamente, pelas ilusões constitutivas de que deformações não existem.

A leitura psicanalítica das organizações - modalidades de vínculo social - instaura-se, segundo Freud (1982g), em tudo que se encontra aquém da vontade racional, sobre aquilo que a razão não poderá jamais ter controle: pulsão de vida e pulsão de morte, amor e ódio do outro, busca da união e da separação.

Ao fazer buracos no imaginário organizacional, Gabriel e Antonacopoulou (2001) consideram que a psicanálise desfaz a afirmação da organização como unidade compacta, sem falhas e não contraditória. Abre-se, assim, o caminho para a superação da dialética do senhor e do escravo hegeliana, cujo primeiro momento reside na incorporação do negativo. O senhor comanda, impõe sua vontade, é livre; e o escravo, coitado, é posto em contato com a condição humana em toda sua rudeza, porém, é privado dos meios que permitiriam viver e pensar a dimensão da liberdade. Enquanto incapazes de sair do círculo vicioso, senhor e escravo partilham da mesma impotência e a única possibilidade de sair desse círculo e abrir-se para o novo é assumir o negativo: o homem como senhor e escravo de si. Aí, então, a autoconsciência começa a se superar, a pensar sua finitude, abre-se à incorporação da força mágica do negativo (em sua expressão mais concentrada, a morte) e transforma-se em razão. A superação dialética (Aufhebung) talvez tenha sido o esquecimento do projeto iluminista que, queimando etapas, buscava transgredir os movimentos, passando diretamente das formas rudimentares do saber à razão.

A partir do momento em que o estudo nos conduziu a compreender a contratransferência como o fenômeno mais complexo e de difícil destrinchamento e contradições, fomos levados a - nas análises - abrir mão da simplicidade capaz de compreender 
a manifestação inerente aos discursos de todos os liderados como sendo fenômenos transferenciais, diretos e elogiosos sem diferencial conceitual - diluindo, dessa forma, todas as díades e os conceitos trabalhados na teoria - projeção-introjeção; idealização (Eu ideal e ideal do Eu) e identificação em um simples bloco de unanimidades e aplausos. Inúmeros problemas podem ter levado a prática desta pesquisa a tal encruzilhada, principalmente a veracidade do carisma do líder, o conhecimento prévio da pesquisadora, o interesse inconsciente na transmissão de uma institucional do programa stricto sensu investigado - fique claro não ser o dos investigadores. Por esse motivo, depois de definido o delineamento, a teorização por díades, foi necessário empreender uma guinada nas análises das entrevistas clínicas, não mais pretendendo verificar o óbvio prescrito por uma teoria secular, mas sim subdividir os conceitos inconscientes inerentes e manifestos na relação líder-liderados de forma individual, porém, buscando conexões, visualizações. O estudo encerrou-se por esgotamento dos trechos discursivos, emitidos somente por 5 entrevistados, além do líder, e também com a finalidade de não romper a trama epistemológica de conceitos originários da Teoria Psicanalítica. 


\section{REFERÊNCIAS}

ARNAUD, G. The contribution of psychoanalysis to organization studies and management: an overview. Organization Studies, v. 33, n. 9, p. 1121-1135, 2012.

ÁVILA, L. A. O Eu é plural: grupos - a perspectiva psicanalítica. Vínculo: Revista do NESME, v. 1, n. 6, p. 39-52, 2009.

DRIVER, M. The lack of power or the power of lack in leadership as a discursively constructed identity. Organization Studies, v. 34, n. 3, p. 407-422, 2013.

ENRIQUEZ, E. A organização em análise. Petrópolis, RJ: Vozes, 1997.

FREUD, S. O inconsciente. In: FREUD, S. A história do movimento psicanalítico, artigos sobre metapsicologia e outros trabalhos. Rio de Janeiro: Imago, 1982a. p. 94-127. (Obras Psicológicas Completas de Sigmund Freud, v. 14).

FREUD, S. Cinco lições de psicanálise, Leonardo da Vinci e outros trabalhos. Rio de Janeiro: Imago, 1982b. (Obras Psicológicas Completas de Sigmund Freud, v. 11).

FREUD, S. O interesse científico da psicanálise. In: FREUD, S. Totem e tabu e outros trabalhos. Rio de Janeiro: Imago, 1982c. p. 115-132. (Obras Psicológicas Completas de Sigmund Freud, v. 13).

FREUD, S. Totem e tabu e outros trabalhos. Rio de Janeiro: Imago, 1982d. (Obras Psicológicas Completas de Sigmund Freud, v. 13).

FREUD, S. Sobre o narcisismo: uma introdução. In: FREUD, S. A história do movimento psicanalítico, artigos sobre metapsicologia e outros trabalhos. Rio de Janeiro: Imago, 1982e. p. 43-62. (Obras Psicológicas Completas de Sigmund Freud, v. 14).

FREUD, S. Psicologia das massas e análise do eu. In: FREUD, S. Além do princípio do prazer, psicologia de grupo e outros trabalhos. Rio de Janeiro: Imago, 1982f. (Obras Psicológicas Completas de Sigmund Freud, v. 18).

FREUD, S. O mal-estar na civilização. In: FREUD, S. O futuro de uma ilusão, o mal-estar na civilização e outros trabalhos. Rio de Janeiro: Imago, 1982g. p. 37-91. (Obras Psicológicas Completas de Sigmund Freud, v. 21).

FREUD, S. Estudos sobre a histeria. Rio de Janeiro: Imago, 1982h. (Obras Psicológicas Completas de Sigmund Freud, v. 2).

FREUD, S. Pulsões e seus destinos. Rio de Janeiro: Imago, 1982i. (Obras Psicológicas Completas de Sigmund Freud, v. 2).

FREUD, S. O ego e o id e outros trabalhos. Rio de Janeiro: Imago, 1982j. (Obras Psicológicas Completas de Sigmund Freud, v. 19).

FREUD, S. Luto e melancolia. In: FREUD, S. A história do movimento psicanalítico, artigos sobre metapsicologia e outros trabalhos. Rio de Janeiro: Imago, 1982k. (Obras Psicológicas Completas de Sigmund Freud, v. 14).

GABRIEL, Y. The unmanaged organization: stories, fantasies and subjectivity. Organization Studies, v. 16, n. 3, p. 477-501, 1995.

GABRIEL, Y. Psychoanalytic approaches to leadership. In: BRYMAN, A. et al. (Ed.). The SAGE handbook of leadership. London: Sage, 2011. p. 393-405.
GABRIEL, Y.; ANTONACOPOULOU, E. P. Emotion, learning and organizational change: towards an integration of psychoanalytic and others perspectives. Journal of Organizational Change Management, v. 14, n. 5, p. 435-451, 2001.

GAULEJAC, V. Gestão como doença social: ideologia, poder gerencialista e fragmentação social. São Paulo: Ideias \& Letras, 2007.

GODOI, C. K. Psicanálise das organizações: contribuições da teoria psicanalítica aos estudos organizacionais. Itajaí, SC: Universidade do Vale do Itajaí, 2005.

GODOI, C. K.; MATTOS, P. L. C. L. Entrevista qualitativa: instrumento de pesquisa e evento dialógico. In: GODOI, C. K.; BANDEIRA-DEMELLO, R.; SILVA, A. A pesquisa qualitativa em estudos organizacionais: paradigmas, estratégias e métodos. 2. ed. São Paulo: Saraiva, 2010. p. 301-324.

GUIMARÃES, L. V. M. Entre o céu e o inferno: confissões de executivos no topo da carreira profissional. $211 \mathrm{f}$. Tese (Doutorado em Administração) - Centro de Pós-Graduação e Pesquisas em Administração, Universidade Federal de Minas Gerais, Belo Horizonte, 2014.

HUMPHREYS, J. et al. Situational narcissism and charismatic leadership: a conceptual framework. Journal of Behavioral and Applied Management, v. 11, n. 2, p. 118, 2010.

ISLAM, G. Identities and ideals: psychoanalytic dialogues of self and leadership. Leadership, v. 10, n. 3, p. 344-360, 2014.

KAËS, R. Os espaços psíquicos comuns e compartilhados: transmissão e negatividade. São Paulo: Casa do Psicólogo, 2011.

KETS DE VRIES, M. The dark side of leadership. Business Strategy Review, v. 14, n. 3, p. 25-28, 2003.

KROHN, A. Intrapsychic impediments to effective leadership. Psychoanalytic Inquiry, v. 32, n. 4, p. 358-367, 2012.

LAPIERRE, L. (Coord.). Imaginário e liderança: na sociedade, no governo, nas empresas e na mídia. São Paulo: Atlas, 1995.

LAPLANCHE, J.; PONTALIS, J. B. Vocabulário da psicanálise. 4. ed. São Paulo: Martins Fontes, 2001.

LÉVY, A. Ciências clínicas e organizações sociais: sentido e crise de sentido. Belo Horizonte: Autêntica/Fumec, 2001.

LÉVY, A. et al. Psicossociologia: análise social e intervenção. Belo Horizonte: Autêntica, 2001.

LICHTMAN, C. The mind of a leaderless organization. Psychoanalytic Inquiry, v. 32, n. 4, p. 412-423, 2012.

LOPES, F. T. Fotografia de família: contribuições da abordagem psicanalítica para o estudo sobre organizações familiares. In: ENCONTRO NACIONAL DA ASSOCIAÇÃO NACIONAL DOS PROGRAMAS DE PÓSGRADUAÇÃO EM ADMINISTRAÇÃO; 2008. Anais... Rio de Janeiro: AnPAD, 2008.

MACCOBY, M. Why people follow the leader: the power of transference. Harvard Business Review, p. 77- 85, 2004. 
Manifestações inconscientes na relação líder-liderado: contribuições da teoria psicanalítica aos estudos organizacionais
Christiane Kleinübing Godoi | Fabíola Radaê Gewehr Cargnin Antônio Giovanni Figliuolo Uchôa
MACHADO, M. N. M. Intervenção psicossociológica, método clínico, de pesquisa e de construção teórica. Pesquisas e Práticas Psicossociais, v. 5, n. 2, 2010.

MALTZ, M. Organizational thinking, leadership and subsequent action: psychoanalysis as a guide? Psychoanalytic Dialogues, v. 22, p. 529-539, 2012.

PAES, K. D.; DELLAGNELO, E. H. L. O sujeito na epistemologia lacaniana e sua implicação para os estudos organizacionais. Cadernos EBAPE. BR, v. 13, n. 3, p. 530, 2015.
STEIN, Mark. When does narcissistic leadership become problematic? Dick Fuld at Lehman Brothers. Journal of Management Inquiry, v. 22, n. 3, p. 282-293, 2013.

STEIN, H.; ALLCORN, S. Good enough leadership: a model of leadership. Organisational and Social Dynamics, v. 14, n. 2, p. 342-366, 2014.

VINCE, R.; MAZEN, A. Violent innocence: a contradiction at the heart of leadership. Organization Studies, p. 1-19, 2014.

Christiane Kleinübing Godoi

Pós-Doutorado na Universidad Complutense de Madrid; Doutorado em Engenharia de Produção pela Universidade Federal de Santa Catarina (UFSC); Professora de Stricto Sensu na Universidade do Vale do Itajaí (Univali), Biguaçu - SC, Brasil. E-mail: chriskg@univali.br

Fabíola Radaê Gewehr Cargnin

Mestrado em Administração pela Universidade do Vale do Itajaí (Univali), Biguaçu - SC, Brasil. E-mail: cargnin.psicologa@gmail.com

Antônio Giovanni Figliuolo Uchôa

Doutorado em Administração pela Universidade do Vale do Itajaí (Univali), Biguaçu- SC, Brasil; Mestrado em Gestão Empresarial pela Escola Brasileira de Administração Pública e de Empresas da Fundação Getulio Vargas (FGV EBAPE), Rio de Janeiro - RJ, Brasil. E-mail: uchoag@yahoo.com.br 